\title{
Reticuloendothelial Hyperplasia
}

National Cancer Institute

\section{Source}

National Cancer Institute. Reticuloendothelial Hyperplasia. NCI Thesaurus. Code C34977.

A greater than normal number of blood cells in the reticuloendothelial system. 